\title{
AMB warns against the use of electronic nicotine delivery devices: Electronic and heated cigarettes
}

\author{
Alerta da AMB sobre o uso de Dispositivos eletrônicos para entrega da nicotina: \\ CIGARRO ELETRÔNICO E CIGARRO AQUECIDO
}

Comissão de Combate ao Tabagismo da Associação Médica Brasileira (AMB)

The Brazilian Medical Association (AMB), which gathers the country's medical specialty societies, goes public to address physicians and the entire Brazilian society regarding the risks related to both safety while handling and the health effects of the consumption of electronic cigarettes, or e-cigarettes, as well as the lack of independent scientific studies on heated cigarettes. The consumption of these products has been reported by their manufacturers in the media and the internet as less harmful to humans, and the fact that it makes their users dependent on nicotine, like any tobacco product, is omitted.

The Brazilian Agency for Health Surveillance (Anvisa, in the Portuguese acronym), the entity responsible for the regulation of tobacco products in Brazil, has already firmly positioned itself in relation to forms of nicotine (dependence-causing substance in any kind of tobacco) release such as electronic smoking devices.

Resolution RDC 46/2009 prohibits the marketing, importation and advertising of any electronic smoking devices - including e-cigarettes and heated cigarettes, especially those claiming to be substitutes of cigarettes, cigarillos, cigar, pipe and similar products, or which are intended to be an alternative to smoking cessation.

AMB's Committee on Tobacco Control warns that there is no scientific evidence that the use of e-cigarettes is effective in reducing traditional cigarette smoking or in stopping smoking.

In traditional cigarette smoke, tobacco is produced, and in turn produces thousands of toxic and carcinogenic substances for both the active smoker and the passive smoker, including carbon monoxide (risk factor for myocardial infarction) and tar alkaloids (carcinogen).

As for e-cigarettes, although there is no combustion of tobacco, the product is not innocuous as it has been wrongly advertised. In this product, nicotine is liquid and, after being heated, it is aspirated and also released into the environment as vapor. Thus, the device mimics, from a behavioral point of view, the conventional cigarette, and carries to the airways substances that are also harmful to its users.

It is a fact that e-cigarette vapor contains several substances in smaller amounts than those found in traditional cigarettes, but on the other hand it contains as many toxic and carcinogenic substances in higher concentrations in the vapor than those found in cigarette smoke, in addition of other toxic substances that are not present in traditional cigarette smoke.

Not only that, these products use flavors and flavoring elements in their composition, which promotes seduction among youngsters for experimentation and smoking initiation. This segment of the market has been historically exploited by the tobacco industry in order to boost the entry of new smokers and increase business profits.

With regard to the new product known as heated cigarette, there is as of yet no available scientific study that has been conducted by the independent research community to avoid conflict of interest with manufacturers.

After all, the tobacco industry has not prioritized, in the course of its history, conveying information about contents and damages inherent in the consumption of its products. First, they denied "believing that nicotine caused addiction" in the American Supreme Court; then they claimed to be "unaware of tobacco-related diseases," although in their own internal documents - required to be made publicly available by the British and American courts - they revealed that they added amphetamine substances, among other health-damaging products.

The tobacco industry has never shown (and will not begin to show) any concern about contributing to technologies for the reduction or even cessation of smoking 
among its loyal consumers because the tobacco industry does not produce goods for humanity. This industry's product kills 7 million people each year (WHO, 2017), of which 156,000 are in Brazil alone (Fiocruz, 2017).

With the available scientific evidence and the robust indicators of current research on the prevalence of smoking in Brazil (Vigitel, Vigescola, PNS-IBGE) that has been showing a significant decline in tobacco experimentation, initiation and consumption in the country, the AMB considers reckless, from the point of view of public health, the entry of these two products into the country, which has been the subject of controversy in other countries.

Finally, considering that the "precautionary principle" should be adopted in the emergence of any technology or product that could potentially affect the health of its users, whose risks have not been adequately measured, the AMB does not recommend the use of either of these two products as reduced-risk devices, neither for reducing cigarette consumption nor for smoking cessation. 